\title{
Determination of antidiabetic compounds from Helicteres isora fruits by oral glucose tolerance test
}

\author{
Govindasami Chandirasegaran ${ }^{1}$, Chakkaravarthy Elanchezhiyan ${ }^{1 *}$, Kavisa Ghosh ${ }^{1}$, Subramaniyan Sethupathy ${ }^{2}$ \\ ${ }^{1}$ Department of Zoology, Annamalai University, Annamalainagar 608 002, Tamil Nadu, India. ${ }^{2}$ Department of Biochemistry, Rajah Muthiah Medical \\ College and Hospital, Annamalai University, Annamalainagar 608 002, Tamil Nadu, India.
}

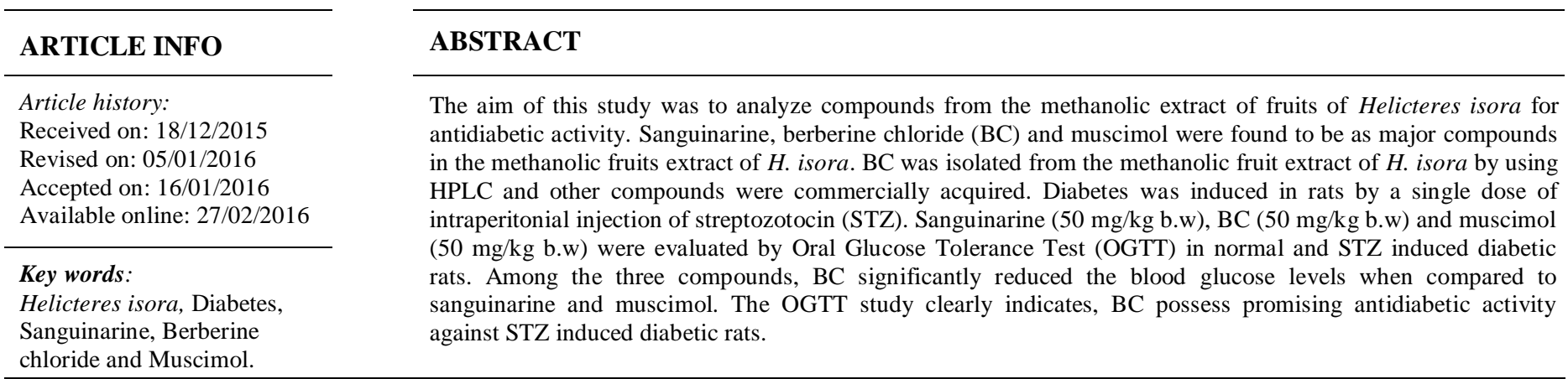

\section{INTRODUCTION}

The Oral Glucose Tolerance test (OGTT) measures the body's ability to use a type of sugar, called glucose that is the body's main source of energy. OGTT, a test of immense value and sentiment, in favor of using fasting plasma glucose concentration alone was seen as a practical attempt to simplify and facilitate the diagnosis of diabetes. Hyperglycemia is an important factor in the development and progression of the complications of diabetes mellitus (Luzi, 1998). Diabetes is becoming the third 'killer' of mankind, after cancer and cardiovascular diseases, because of its high prevalence, morbidity and mortality (Kim et al., 2006). The International Diabetes Federation (IDF) estimates the total number of diabetic subjects to be around 382 million and this is further to be set to rise to 592 million by the year 2035 (IDF, 2013). Currently available therapies for diabetes include insulin and various oral antidiabetic agents such as sulfonylureas, biguanides and glinides. Many of them have a number of serious adverse effects; therefore, the search for more effective and safer hypoglycemic agents is one of the important areas of investigations (Patel et al., 2012). Many herbs and plants have been described as possessing

\section{* Corresponding Author}

Elanchezhiyan Chakkaravarthy, Department of Zoology, Annamalai University, Annamalainagar 608 002, Tamil Nadu, India.

mailid: chezhiyanzooau@gmail.com hypoglycemic activity when taken orally (Rajan et al., 2012). $H$. isora is a large arborescent shrub of the family Sterculiaceae and it is commonly called as East-Indian screw tree (Drymock et al., 1890). It is used as an anthelmintic, antispasmodic, antipyretic, antidiarrheal, antidysenteric (Al Yahya, 1986). The fruits of $H$. isora have also been reported to possess antidiabetic activity (Boobathy raja et al., 2010). According to Elanchezhiyan et al, compounds, i.e., sanguinarine, BC and muscimol. Hence, this investigation was designed to identify the most promising antidiabetic compound from the methanolic extract of fruits of $H$. isora by OGTT.

\section{MATERIALS AND METHODS}

\section{Collection \& Preparation of Plant Material}

The fruits of $H$. isora were collected in the month of January 2015 from the natural habitats of Tirunelveli, Tamil Nadu, India. The plant was identified at the herbarium of Department of Botany, Annamalai University.

A voucher specimen (Herbarium No. DDE/HER/65) was deposited in the Department Herbarium for future reference.The fruits were washed three times thoroughly with running tap water to remove soil particles and adhered debris and finally with sterile distilled water. The fruits were cut, shade dried, ground into fine powder and stored in airtight container for further use. (2014) methanolic extract of $H$. isora fruits possess three major 


\section{Plant Extraction Method}

A cold extraction method was followed. Portions (100g) of the fresh and dry samples were weighed, added to conical flasks containing $1000 \mathrm{ml}$ of methanol and left for $48 \mathrm{~h}$. The mixtures were filtered under vacuum pressure and the filtrates were concentrated using rotary evaporator and subjected to the various activity studies.

\section{Isolation and Identification of Active compound from fruits of H. isora through HPLC}

Our previous work has shown that the methanolic crude extract of fruits of $H$. isora was having antidiabetic activity when compared to chloroform, acetone, ethyl acetate and ethanol extracts (Elanchezhiyan et al., 2014). The major compounds were identified from $H$. isora methanolic extract by GC-MS (Elanchezhiyan et al., 2014). The major compounds, sanguinarine (Nanjing Zelang Medical Technology Co., Ltd) and muscimol (Sigma-Aldirich) were procured commercially, whereas, BC was purified from the methanolic extract using semi preparative HPLC (Shimadzu LA-2000) using C18 Reverse Phase Column and as a mobile solvent phase of Acetonitrile/ $0.1 \%$ TFA water $(60: 40)$.

\section{Animals}

Healthy male albino Wistar rats weighting180-200g were used for this experiment. During the experimental period, standard pellet diet provided to rats and water ad libitum. This study was approved by the Animal Ethics Committee of Rajah Muthiah Medical College and Hospital, Annamalai University (Reg No 166/1999/CPCSEA, Proposal No. 1085).

\section{Induction of diabetes}

Diabetes was induced in rats by intraperitonial injection of a freshly prepared solution of STZ $(50 \mathrm{mg} / \mathrm{kg} \mathrm{b.w})$ in citrate buffer (0.1M; pH 4.5). After the three days STZ induced rats were having fasting blood glucose above $230 \mathrm{mg} / \mathrm{dl}$ were considered as diabetic that animals were used for further study.

\section{Oral Glucose Tolerance Test (OGTT)}

A total of 36 rats was used in this experiment and divided into six groups, each group consists of 6 rats. Sanguinarine was dissolved in DMSO (0.5\%) and BC, muscimol and glibenclamide was dissolved in water.

Group 1- Normal Control rats

Group 2- Diabetic Control rats

Group 3- Diabetic + Sanguinarine $(50 \mathrm{mg} / \mathrm{kg}$ b.w $)$

Group 4- Diabetic + BC (50 mg/kg b.w)

Group 5- Diabetic + Muscimol (50 mg/kg b.w)

Group 6- Diabetic + Glibenclamide (6mg/kg b.w)

After1 hour of drug administration, the rats of normal and diabetic groups were orally treated with $2 \mathrm{~g} / \mathrm{kg}$ of glucose. The blood samples were collected from all the rats from the tail vein at 0, 30, 60, 90, 120 minutes. The blood glucose level was estimated by the method of Trinder, (1969).

\section{Statistical analysis}

Values are given as means \pm S.D. for six rats in each group. Data were analyzed by one-way analysis of variance followed by Duncan's Multiple Range Test (DMRT) using SPSS version 15 (SPSS, Chicago, IL). The limit of statistical significance was set at $\mathrm{p}<0.05$.

\section{RESULTS AND DISCUSSION}

Diabetes mellitus of long duration is associated with several complications such as atherosclerosis, myocardial infarction, neuropathy, etc. These complications has long been assumed to be related to chronically elevated blood glucose levels. Diabetes mellitus causes disturbances in the uptake of glucose as well as glucose metabolism. STZ induced diabetic model very useful to study the activity of hypoglycemic agents (Szkuclelski, 2001). The experiment showed that the OGTT measures the body's ability to use glucose, the body's main source of energy (Gold, 1970). This test can be used to diagnose pre-diabetes and diabetes. The active compound $\mathrm{BC}$ was purified from the methanolic extract of $H$. isora fruits with Retention time of 13.51 and it was confirmed by comparing it with that of commercially available BC (Fig. $1 \& 2$ ).

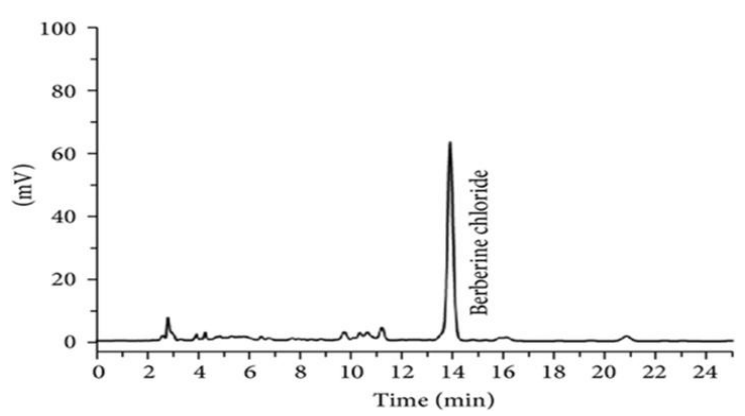

Fig. 1: HPLC chromatogram of Berberine chloride.

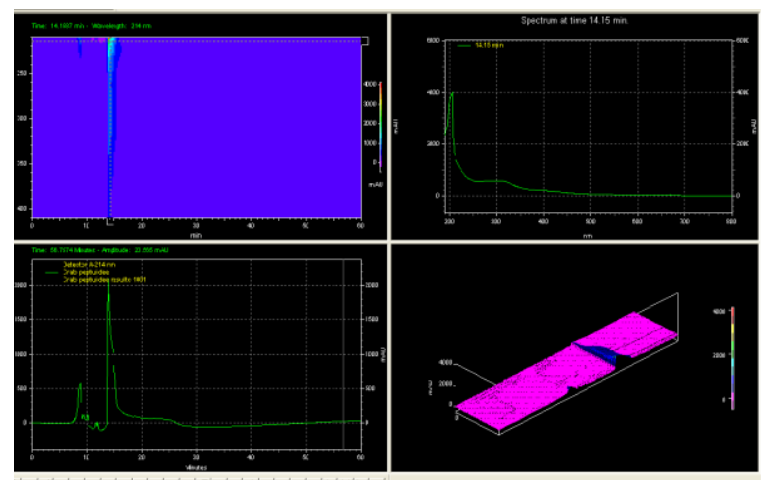

Fig.2: 3D view of HPLC chromatogram of Berberine chloride.

Table 1 illustrates the effect of sanguinarine, BC and muscimol on normal and experimental animals. In diabetic control group shows the increased level of blood glucose when compared to normal control rats. The blood glucose levels were significantly decreased in BC treated groups when compared with sanguinarine and muscimol treated groups. BC reduced blood glucose levels were similar to that of glibenclamide treated groups. 
Table 1: Effect of SG, BC and MS on oral glucose tolerance test.

\begin{tabular}{|c|c|c|c|c|c|}
\hline \multirow{2}{*}{ Groups } & \multicolumn{5}{|c|}{ Blood glucose mg/dl } \\
\hline & O minute & 30 minutes & 60 minutes & 90 minutes & 120 minutes \\
\hline $\mathrm{NC}$ & $84.51 \pm 6.44$ & $87.46 \pm 6.69$ & $86.35 \pm 6.58$ & $88.96 \pm 6.81$ & $92.42 \pm 7.04^{\mathrm{a}}$ \\
\hline $\mathrm{DC}$ & $242.42 \pm 18.56$ & $246.60 \pm 18.78$ & $251.59 \pm 19.26$ & $257.23 \pm 19.59$ & $262.73 \pm 20.11^{b}$ \\
\hline $\mathrm{D}+\mathrm{SG}(50 \mathrm{mg} / \mathrm{kg} \mathrm{b} . \mathrm{w})$ & $245.60 \pm 18.70$ & $241.57 \pm 18.49$ & $239.41 \pm 18.23$ & $236.71 \pm 18.12$ & $234.94 \pm 17.89^{c}$ \\
\hline $\mathrm{D}+\mathrm{BC}(50 \mathrm{mg} / \mathrm{kg} \mathrm{b} . \mathrm{w})$ & $244.66 \pm 18.63$ & $240.62 \pm 18.42$ & $231.06 \pm 17.59$ & $220.31 \pm 16.86$ & $207.15 \pm 15.77^{\mathrm{d}}$ \\
\hline $\mathrm{D}+\mathrm{MS}(50 \mathrm{mg} / \mathrm{kg} \mathrm{b} . \mathrm{w})$ & $251.27 \pm 19.13$ & $248.44 \pm 19.02$ & $246.58 \pm 18.78$ & $242.99 \pm 18.60$ & $240.69 \pm 18.33^{\mathrm{c}}$ \\
\hline $\mathrm{D}+\mathrm{GC}(50 \mathrm{mg} / \mathrm{kg} \mathrm{b.w})$ & $235.80 \pm 17.96$ & $229.54 \pm 17.57$ & $221.86 \pm 16.89$ & $211.86 \pm 16.17$ & $201.96 \pm 15.38^{\mathrm{d}}$ \\
\hline
\end{tabular}

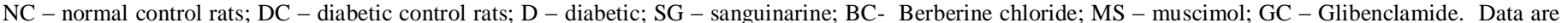
given as a mean \pm S.D from six rats in each group. Values not sharing a common superscript differ significantly at $\mathrm{p}<0.05$ (DMRT).

Thus, this experiment clearly shows that BC possesses antidiabetic activity and the activity was comparable to that of glibenclamide. Some phytochemical compounds such as polysaccharides, terpenes, tannins, steroids and alkaloids have been implicated in the antidiabetic activities of plants (Wadood et al., 2003; Koyama et al., 2004). H. isora fruits and plant extracts have been previously reported to possess antidiabetic activities (Gupta et al., 2009; Kumar and Singh, 2014; Dayal et al., 2015). Phytochemical analysis of the methanolic extract of $H$. isora fruits revealed the presence of three major constituents; sanguinarine, $\mathrm{BC}$ and muscimol, which could be responsible for the antidiabetic activity. Among the three compounds, BC possess highest antidiabetic activity, as observed from the results of oral glucose tolerance test. The antidiabetic activity of $\mathrm{BC}$, an alkaloid, was comparable to the results presented by Sharma et al, (2010). Glibenclamide has been used for many years to treat diabetes, which bring out hypoglycemic condition by increased insulin secretion from remnant pancreatic $\beta$-cells (Dongare et al., 2012). Thus, from this study, it is evident that a reduction in blood glucose levels by $\mathrm{BC}$ was comparable to that of blood glucose lowering effects of glibenclamide in STZ treated rats.

\section{CONCLUSION}

Among the three treatment compounds, sanguinarine, BC and muscimol, BC showed prominent glucose lowering effects. Hence, this result clearly demonstrates, that $H$. isora fruits showed antidiabetic activity due to the presence of BC in its fruits. Further studies need to be carried out to identify the mechanism of action and the long term effects of $\mathrm{BC}$, extracted from $H$. isora fruits, on mammalian diabetic models.

\section{ACKNOWLEDGEMENT}

The authors wish to acknowledge the University Grants Commission, New Delhi, project no.41-178/2012/(SR) for funding this work and also extend their thanks to the Department of Zoology (UGC - SAP Sponsored), Annamalai University, for providing the infrastructure facility and support.

\section{REFERENCES}

Al Yahya MA. Phytochemical studies of the plants used in traditional medicine of Saudi Arabia. Fitoterapia, 1986;57:179-82.

Boopathy Raja A, Elanchezhiyan C, Sethupathy S. Antihyperlipidemic activity of $H$. isora fruit extract on streptozotocin induced diabetic male Wistar rats. Eur Rev Med Pharmacol Sci, 2010; 14: 191-196. Dayal R, Singh A, Ojha RP, Mishra KP. Possible therapeutic potential of Helicteres isora (L.) and it's mechanism of action in diseases. J Med Plants Stud, 2015; 3: 95-100.

Dongare V, Kulkarni C, Kondawar M, Magdumb C, Haldavnekar V, Arvindekar A. Inhibition of aldose reductase and anticataract action of transanethole isolated from Foeniculum vulgare Mill. fruits, Food Chem, 2012; $132: 385-390$.

Drymock W, Warden CJH, Hooper D. 1890. In: Pharmacographica Indica. Kegan P, Treneb, editors. London: Trubner and Co. p. 232.

Elanchezhiyan C, Kumaravel K, Bilal Ahmad Bhat, Sethupathty S. Phytochemical and Metabolite Fingerprinting of Helictres isora Through Gas chromatography and Mass Spectrum analysis. J Pharm Res, 2014; 8: 243-247.

Gold AH. The effect of diabetes and insulin on liver glycogen synthetase activation. J Biol Chem, 1970; 245-903.

Gupta RN, Pareek A, Suthar M, Rathore GS, Basniwal PK, Jain D. Study of glucose uptake activity of Helicteres isora Linn. Fruits in L-6 cell lines. Int J Diab Dev Ctries, 2009; 29: 170-173.

International Diabetes Federation. IDF Diabetes Atlas, 6th edn. Brussels, Belgium: International Diabetes Federation, 2013.

Kim SH, Hyun SH, Choung SY. Anti-diabetic effect of cinnamon extract on blood glucose in $\mathrm{db} / \mathrm{db}$ mice. J Ethnopharmacol, 2006; 104:119-123.

Koyama Y, Abe K, Sano Y and Shizaki L: Effect of green tea on gene expression of hepatic gluconeogenic enzyme in vivo. Planta Medica, 2004; 70: 1100-2.

Kumar N, Singh AK. Plant profile, phytochemistry and pharmacology of Avartani (Helicteres isora Linn.): A review. Asian Pac J Trop Biomed, 2014; 4: S22-26.

Luzi L. Pancreas transplantation and diabetic complications. N Eng J Med, 1998; 339:115-117.

Patel DK, Prasad SK, Kumar R, Hemalatha S. An overview on antidiabetic medicinal plants having insulin mimetic property. Asian Pac J Trop Biomed, 2012; 2: 320-330.

Rajan M, Kumar VK, Kumar PS, Swathi KR, Haritha S. Antidiabetic, antihyperlipidaemic and hepatoprotective activity of methanolic extract of Ruellia tuberose Linn. leaves in normal and alloxan induced diabetes. J Chem Pharm Res, 2012; 4: 2860- 2868.

Sharma B, Salunke R, Balomajumder C, Daniel S, Roy P. Antidiabetic potential of alkaloid rich fraction from Capparis decidua on diabetic mice. J Ethnopharmacol, 2010;127: 457-462.

Szkudelski T. The mechanism of alloxan and streptozotocin action in B cells of the rat pancreas. Physiol Res, 2001; 50: 536-546.

Wadood N, Wadood A, Nisar M. Effect of Ficus religiosa on blood glucose level and total lipid level of normal and alloxan diabetic rabbits. J Ayub Med Coll Abbottabad, 2003; 15: 40-42.

\section{How to cite this article:}

Govindasami C, Chakkaravarthy E, Ghosh K. Determination of antidiabetic compound from Helicteres isora by oral glucose tolerance test. J App Pharm Sci, 2016; 6 (02): 172-174. 